\title{
FATÔRES DO DESENVOLVIMENTO (*)
}

\author{
JOSÉ PETRELLI GASTALDI \\ Docente Livre de Economia Política
}

\section{1 - O PROCESSO DO CRESCIMENTO}

No dizer de Delfim Netto, "é preciso lembrar que o desenvolvimento econômico é um processo global de transformação, que implica em modificações quantitativas e qualitativas no sistema produzido; em modificação das relações entre os indivíduos e que altera não apenas a estruiura econômica, mas também os valôres básicos e as formas de comportamento de tôda a sociedade tradicional" (Antonio Delfim Netło "O papel do empresário privado no Processo de Desenvolvimento Econômico" "Problemas Brasileiros", n. 24 , pág. 2.).

Verifica-se, por essa definição do ilustre economista que o desenvolvimento econômico, além de implicar em processo global de transformação da estrutura econômica vigente, possue fundamentos também sociológicos.

Não basta pretender aumentar a quantidade de capital em relação à mão de obra, lembra o mesmo autor, para realizar o desenvolvimento. Muito mais importante do que aumentar a quantidade do fator capital "é a descoberta de novas formas produtivas (novos tipos de combinação entre o capital, e a mão de obra), porquanto o papel preeminente no processo de desenvolvimento econômico cabe à incorporação das novas técnicas produtivas e não apenas à acumulação (ídem, ídem, pág. 2).

Pode ocorrer, como se evidencía, um processo de desenvolvimento pelo melhor aproveitamento dos fatôres produtivos e nítida melhoria tecnológica, mesmo que os índices do rendimento individual não superem, por vêzes, os limites pré-estabelecidos em es-

* O tema constante do título acima constitui o Capítulo 2.0 do Livro Primeiro da obra do aludido Professor, sob o título "A Economia Brasileira e os Problemas do Desenvolvimento" 
calas de rendas mais ou menos variáveis. Não devemos pois, limitarnos à medir o gráu do desenvolvimento pelo índice exclusivo da renda "per capita", conforme já o acentuámos e de acôrdo, ainda, com o ensinamento de KINDLEBERGER (Charles P. Kindleberger "Desarrollo Econômico", pág. 1).

\section{2 - ÍNDICES DO CRESCIMENTO ECONÔMICO}

O Diretor da USAID no Brasil, Dr. Donnor Lion, lembra, com mui. ta oportunidade, "que o desenvolvimento econômico visa aumentar - número de bens e serviços disponíveis para à utilização e aproveitamento por parte do povo. Todos estamos de acôrdo, porém que o desenvolvimento econômico satisfatório é indispensável, mas não é suficiente. Ao nos dedicarmos à aceleração de realizações materiais, procuramos buscá-las dentro de um ambiente democrático, tanto social como político" (Suplemento do Nordeste, in Folha de São Paulo, ed. 21-8-66). E' de fato, sem liberdade social e política não pode haver democracia social e econômica, e sem ela de nada valerá o desenvolvimento material.

Pelos cânones admitidos quase que unânimemente, os países que apresentam renda "per capita" inferior a 250 dólares anuais, ainda não iniciaram a sua fase inicial de expansão cumulativa; não possuem, ainda, a suficiente infraestrutura econômica e as condições tecnológicas mínimas, para a aceleração econômica. Acima dêsse limite inferior e até aproximadamente 500 dólares de renda "per capita", considera-se que o país que apresentar tal rendimento se encontra em fase de desenvolvimento, que será pleno ao ultrapassar o této de 800 dólares anuais.

Jamais poderemos prescindir de tais índices, pois segundo o gráu de intensidade do crescimento da renda que se tenha por alvo, será previsível a intensidade da procura por setores de produção.

Em nosso país, conforme com as últimas estatísticas, a renda "per capita" teria atingido, globalmente, o índice de 320 dólares anuais. Mas, essa renda, se considerada regionalmente, sofre oscilações bastante sintomáticas, ultrapassando de 350 dólares em São Paulo e não atingindo sequer 90 dólares nos Estados de Piauí e Sergipe. Estatísticas internacionais indicam 178 dólares para a renda per capita brasileira.

De considerar, outrossim, a impropriedade de bitolar os índices do crescimento econômico por moeda estrangeira, pois, inevitàvelmente, traduzindo-se o consumo real da população traduzido em cruzeiros deverá ser convertido em moeda americana, para se po- 
der comparar, inversamente, o poder aquisitivo do cruzeiro em bens e serviços nos Estados Unidos e o poder aquisitivo, com a mesma tradução, no Brasil.

Kindleberger menciona um exemplo extraído de inquéritos levados a efeito por Millikan: "O resultado dos cálculos efetuados por M. F. Millikan nos indica que a renda real dos países asiáticos (excluindo o Oriente Médio), calculada por meio de estimativas da renda em moeda local convertida ao tipo oficial de câmbio, foi de 58 dólares per capita em 1950, conquanto seja mais provável que êsse resultado se aproximasse dos 195 dólares se fôsse levado em conta o corretivo sistemático do cálculo. Os resultados comparáveis referentes à África são de 48 e 177 dólares. E. E. Hagen observou que a renda real da Birmânia é estimada em 300 por 100 na medida monetária e aventou a hipótese de que, quanto mais subdesenvolvido está um país, tanto mais a sua renda monetária convertida a um tipo de câmbio determinado subestima a renda real" (Charles P. Kindleberger, ob. cit., pág. 2).

\section{3 - OS ÍNDICES MUNDIAIS DO DESENVOLVIMENTO}

Em levantamento procedido pelo Centro de Estudos Internacionais do Instituto de Tecnologia de Massachussets, deparamos com os índices de renda média "per capita" em pràticamente todos os países do mundo; tal levantamento indica, para o Brasil, rendas de 112 a 215 dólares em 1940 e 1950.

Citando elementos do Grupo Misto BNDE - Cepal, verificamos que a renda média per capiła da América Latina, em 1953, era idêntica a dos Estados Unidos em 1840. Em 1953 a renda média per capiła dos Estados Unidos era, já da ordem de 2.000 dólares, significando que a da América Latina (248 dólares), equivalia a $1 / 8$ da norte americana à taxa anual de $2,4 \%$. esta renda média per capita atingiria a cifra de 666 dólares dentro de 42 anos. Pressupondo que o crescimento da renda per capiła norte-americana prosseguisse com a taxa média de 2,0 por cento ao ano, a América Latina sòmente conseguiria equiparar a sua à rénda dos Estados Unidos dentro do prazo mínimo de 252 anos - (Análise e Projeções do Desenvolvimento Econômico, Grupo Misto BNDE - Cepal, 1957, pág. 14).

Em 1959, a renda nacional "per capita" dos principais países, já havia sofrido sensíveis modificações. Pela conversão à taxa média ponderada global do câmbio dêsse ano a renda média per capita no Brasil era de 22.750 cruzeiros ou 168 dólares, enquanto a norteamericana era de 2.232 dólares, a canadense de 1.433 dólares a da 
Venezuela de 856 dólares e a da Itália de 457 dólares. A Argentina figurava no quadro com 256 dólares, o México com 262, a India com 66, Israel com 822, Alemanha com 870 e Portugal com 210 dór lares (Rev. "Paraná Econômico" Setembro 1961, pág. 28 "Quadro com fonte da United Nations, "Statiscal Yeabock", 1960 e "International Financial Statístics", abril 1961").

Um simples olhar sôbre tal quadro impele o observador à várias deduções, demonstrativas doș imponderáveis do aferimento do processo do desenvolvimento com base exclusiva nos índices do rendimento médio "per capita". A Venezuela, como sabemos, é um país com condições de industrialização bastante inferiores às do Brasil; apresentava, porém, índice de 322 dólares em 1949, 533 dólares em 1953 e 856 dólares de renda média "per capita" em 1959. Em contraposição, a Itália, nação de condições tecnológicas bastante superiores às da Venezuela, figurava com os índices de 235 dólares em 1949, 307 dólares em 1953 e 457 dólares em 1959.

\section{4 - OUTROS PADRÕES DE AFERIMENTO DO PROCESSO DO DESENVOLVIMENTO}

Necessário se torna, assim recorrer-se a outras modalidades de aferimento do processo do crescimento econômico; poder-se-ia ado. tar, por exemplo, o índice decorrente da divisão do produto nacional bruto pelo contingente da população ativa, ao invés de se proceder ao cálculo pelo total da população; também poder-se-ia adotar o critério da produtividade real, muito mais consistente do que os índices relativos aos níveis de vida.

Não podemos adotar, para o processo de expansão, modêlos estrangeiros estereotipados, porquanto, conforme nos lembra Gudin "o exame da história do desenvolvimento econômico nos principais países não revela a uniformidade do modêlo, antes pelo contrário" (Eugênio Gudin "Desenvolvimento Econômico e Capital" Carta Mensal, Ano VI, n. ${ }^{\circ}$, pág. 5). O Brasil e os países da América Latina em geral, possuem cêrca de 50 por cento da sua população ativa na agricultura, sendo bastante ínfimo o capital com que trabalha um operário latino-americano (1.550 dólares-, comparativamente ao capital acumulado e disponível para o operário norte-americano $(8.000$ dólares- (Raul Prebisch, "Relações entre crescimento da população, formação de capital e as oportunidades de emprêgo nos países sub. desenvolvidos", "Rev. Econômica Brasileira", pág. 140, n. 3)". A possibilidade de a América Latina aproximar-se da densidade de capital disponível pelo trabalhador norte-americano é bastante remota no tempo e no espaço, conforme já ficou acentuado. De outro. lado, 
capacidade de capitalização dos países mais desenvolvidos, adotam, embora os países latino-americanos tentem assimilar a técnica e a simultâneamente suas formas de consumo incompatíveis com a renda individual dos seus habitantes. A propaganda e o anseio natural por um melhor padrão de vida, diminuem a propensão da capitalização na proporção direta do aumento da propensão de consumo.

Apesar dos renovados esforços das administrações latino-americanas e dos planos internacionais de ajuda econômica para êste hemisfério, o seu desenvolvimento econômico não tem demonstrado um crescimento promissor. Ainda recentemente, sob o título "Decepcionam os Subdesenvolvidos", foi publicada oportuna opinião a respeito, em importante órgão da imprensa paulista. O seu correspondente em Nova lorque nos dá conta do contido em importante Relatório publicado pela Conferência de Comércio e Desenvolvimento das Nações Unidas (United Nations Conference ou Trade and Development (UNCTAD) qualificou de "profundamente decepcionante" o progresso econômico dos países subdesenvolvidos".

Apontando as causas do lento progresso, acentua que o fluxo líquido dos recursos internacionais é ainda inadequado; o volume de importações feitas pelos países subdesenvolvidos aumenta morosamente e são necessários ḡãandes esforços para mobilizar os recursos internos. Durante os primeiros quatro anos da Década do Desenvol. vimento das Nações Unidas, o Produto Nacional Bruto dos países subdesenvolvidos aumentou na proporção de pouco mais de $4 \%$, enquanto o limite mínimo de aumento para a década estava prevista em $5 \%$.

¿O Relatório demonstra que, se o crescimento da população dos países desenvolvidos fôr tomado em consideração, a impropriedade do índice de crescimento se torna ainda mais aparente. A renda nacional bruta "per capita" dessas nações aumentou apenas em 1,5\% enquanto nos países desenvolvidos o índice "per capita" era de $4 \%$. Em alguns aspectos a situação do "Terceiro Mundo" parece pior do que há dez ou quinze anos passados, quando muitos países ainda se encontravam sob administração colonial". (John Macvane "Decepcionam os Subdesenvolvidos", in- "Estado de São Paulo", ed. de 16-8 $\left.-966^{\prime \prime}\right)$.

O processo de desenvolvimento, portanto, deve fundamentarse em um conjunto de condições, a se somarem para poderem meIhor caracterizar os padrões econômicos de melhoria coletiva. A técnica, as instituições sociais e políticas, o aprendizado profissional, o gráu de cultura das elites e a densidade da instrução pública, 0 incentivo às iniciativas, a política tributária, o aperfeiçoamento e a 
difusão dos meios de transporte, a assistência social e o carinho para com a saúde coletiva, representam indiscutíveis fatôres de propulsão ou de expansão social e econômica, com os necessários efeitos de propagação.

Lauchlin Currie, renomado economista, em recente obra premiada pela Sociedade de Desenvolvimento Internacional - "Acelerating Development", sugere que o desenvolvimento seja avaliado por outros padrões que não a medida do PNB ou da renda per capita.

Devemos, declara, substituir o Planejamento Econômico por um "Programa de Transformação". Não devemos fixar como objetivo a obtenção de determinada taxa estatística de desenvolvimento, mas sim a obtenção de metas específicas e concretas: tantos emprêgos urbanos por ano; tal percentagem de crianças nas escolas; tantas casas para os trabalhadores. E o programa, conforme o mesmo autor, deve orientar-se para o consumo e não para a inversão.

\section{5 - O DESENVOLVIMENTO E AS DISPARIDADES REGIONAIS}

Acresça-se, ainda, que aumentando a complexidade para o im. pulso ao crescimento ou expansão econômica, surgem obstáculos de tôda a sorte, como o das disparidades regionais em regiões ou zonas em fase de desenvolvimento. "Mesmo no caso de países como os Estados Unidos e a Suécia, onde, no século passado, a emprêsa podia explorar uma situação particularmente favorável no tocante aos recursos naturais, e onde, igualmente, existiam. outras condições excepcionalmente vantajosas para o progresso econômico, e não menos no plano cultural, o desenvolvimento não foi tal, que os países inteiros se vissem envolvidos num processo de expansão mais ou menos homogêneo e simultâneo. Estudando a questão mais de perto, descobriremos grandes disparidades. Nos Estados Unidos, por exemplo, quase todo o Sul era até bem recentemente uma região em grande parte estagnada; paralelamente, o aparecimento, algumas gerações atrás, de grandes oportunidades agrícolas nas regiões inexploradas do oeste americano, deixou extensas zonas rurais na Nova Inglaterra numa decadência de que mais algumas delas não conseguiram, ainda hoje, recuperar-se" (Gunnar Myrdal) "Desenvolvimento e Sub-Desenvolvimento", Rev. Conselho Nacional de Economia, Ano VII, n. ${ }^{\circ} 1$, pág. 40.

As disparidades regionais, no Brasil, são bastante acentuadas, constituindo-se em ponderável ponto de estrangulamento ao processo de equação para o nosso decenvolvimento. Também o nosso ponderável índice de crescimento demográfico vem aumentar a delicadeza da problemática, porquanto entre nós ocorre similaridade com 
esta observação de Gambs: "As populações grandes e que se tornam cada vez maiores, especialmente as da Ásia, parecem consumir imediatamente todo o fruto dos seus ganhos econômicos. Assim pouco podem elas extrair da crescente produção atual afim de economizarem para adquirir máquinas e arados melhores e outras coisas mais duráveis que são necessárias para sairem da pobreza direta e enveredarem pé:o caminho do verdadeiro progresso" (John S. Gambs, obr. cit., pág. 48)".

\section{6 - DIFICULDADES MODERNAS PARA O DESENVOLVIMENTO}

Atualmente as pressões e os obstáculos que os países subdesenvolvidos sofrem, são muito superiores aos percalços iniciais enfrentados pelos países já desenvolvidos. A economia norte-americana, nos seus primordios - como ocorreu com a do Canadá, França, etc. - não possuia os encargos com que se defrontam atualmente as economias do Brasil, da Argentina ou do México, referentes às verbas necessárias para a saúde pública, ensino primário e assistência social, sem citar outros gastos forçados e inadiáveis. Conforme vimos, em 1900 a população dos Estados Unidos era de 75 milhões de habitantes, mas, em 1789, havia sòmente 3 milhões de pessoas nos Estados Unidos. No início do presente século os encargos do Tesouro dos Estados Unidos e a Política Fiscal não possuiam a fôrça de compressão atualmente observada na economia brasileira, quando sòmente a emprêsa sofre o ônus de notável soma de encargos sociais, a se refletir forçosamente no custo de produção e no preço das mercadorias.

Tal circunstância é reconhecida pelos economistas modernos: "Naturalmente, a situação nos países menos desenvolvidos dos dias atuais não é a mesma, exatamente, daquela que existiu nos Estados Unidos do século XIX. Assim, por exemplo, muitos países asiáticos de hoje têm grandes populações, enquanto os Estados Unidos dos primeiros tempos de sua história tinham uma população reduzida. Êste fato torna mais difícil a tarefa ẹconômica moderna de países como a India, que a enfrentada pelos americanos nos seus primórdios como nação "(James Calderwood e Harold J. Bienvenu, ob. cit. pág. $119)^{\prime \prime}$.

As condições atuais vieram introduzir substancial modificação no processo do desenvolvimento ou no processo do crescimento econômico. Não basta, hoje, como ocorreu no início das economias atualmente desenvolvidas, pura e simp!esmente adotar o processo da acumulação de capital, porquanto, no dizer de Delfim Netto "o fenômeno do desenvolvimento tem mais aspectos qualitativos do que geral. 
mente se admite e que qualquer tentativa de reduzí-lo a um simples aumento da quantidade de capital por unidade de mão-de-obra pode levar a sérios enganos" (Antonio Delfim Netto, trab. cit., pág. 3)". Não mais é possível dissociar a melhoria da tecnologia do aumento de capital. No processo econômico hodierno "não basta a capacidade de criar excedentes para acelerar o desenvolvimento, pois êste se realiza apenas quando o excedente é reintegrado no processo produtivo na forma de novas combinações tecnológicas, isto é, na forma de capital essencialmente diverso daquele que predomina no sistema econômico" (ídem, ídem, trab. cit. pág. 3)".

Confirma-se, assim, a nossa assertiva de que as economias atuais, menos desenvolvidas, se defrontam com problemas muito mais delicados e onerósos, para iniciarem o seu processo de expansão. A educação, na atualidade, representa o investimento mais necessário para acelerar o crescimento econômico. "Não basta, assim, criar um excedente; é preciso saber como utilizá-lo de maneira a acelerar ao máximo a incorporação de técnicas produtivas mais eficientes diante das disponibilidades dos fatôres de produção. "(Idem, ídem, trab. cit. pág. 3)".

O desenvolvimento brasileiro jamais poderá se acelerar, sem que seja intensificado o indispensável preparo profissional técnico e científico, sem o qual não se poderá assimilar a tecnologia existente e criar aquela mais ajustada à sua disponibilidade de fatôres.

\section{7 - PONTOS DE ESTRANGULAMENTO PARA A EXPANSÃO ECONÔMICA BRASILEIRA}

As dificuldades a serem enfrentadas e vencidas pelos países menos desenvolvidos, na atualidade, são muito mais numerosas e de amplitude muito mais ponderável do que aquelas enfrentadas pe. los países na fase inicial do seu progresso econômico, há um século, conforme já ficou analisado.

Tais obstáculos avultam no caso das economias ainda fundamentadas na atividade primária e com ponderável contingente de mão de obra nesse setor, porquanto: "Por diversos motivos, os preços no mercado mundial para produtos primários, que no presente constituem a maior parte das exportações feitas pelos países subdesenvolvidos, mostram flutuações violentas de mês a mês e de ano a ano. As variações resultantes em suas rendas de exportação geralmente montam a somas muito maiores do que tôdo o auxílio econômico estrangeiro reunido. Medidas para estabilizar tais preços, portanto, seriam meios poderósos de melhorar as condições econômicas nos países subdesenvolvidos" (Gunnar Myrdal "O Estado do Futuro", pág. 237"). 
Ainda para Myrdal, na democracia do típo ocidental, o problema de conseguir a estabilidade monetária com pleno emprêgo pode apenas ser solucionado de modo pienamente satisfatório pela elevação do nível geral de educação (ídem, ídem pág. 127").

Apesar de tais óbices, devemos ter presente a idéia do desenvolvimento econômico, a qual, no dizer de José Augusto "é hoje a preocupação dominante em tôdas as nações" (José Augusto "Instituições políticas e economia", Carła Mensal, n. 4, pág. 23").

Vale lembrar, nesta altura, frente a tais circunstâncias, o judicioso conselho contido na encíclica "Mater et Magistra", do inolvidável João XXIII.

"O problema mais importante da nossa época é, talvez, - das relações entre comunidades políticas econômicamente desenvolvidas e aquelas em vias de desenvolvimento econômico. As primeiras gozam de um nível de vida elevado, as outras sofrem privações muitas vêzes graves".

Percebe-se, assim, que o desenvolvimento econômico brasileiro, a criar os seus lineamentos a partir da década 1950 - 1960, defronta-se com dificuldades de monta, que não foram enfrentadas por outros países na década 1870-1880 ou no início do século, com sistemas sociais que não sofriam as pressões modernas, o que originou a seguinte exclamação de Themístocles Cavalcanti:

"Estamos vivendo uma época profundamente revolucionária e não é sem uma certa perplexidade que encaramos a maioria dos problemas científicos e humanos, porque frequentemente vemos os fatos desmentir aquilo que se afirmava como definitivo, por muitas gerações. E a pergunta se repete: será que tôdo êsse sistema econômico, social e político que chamamos a nossa civilização, ou a civilização ocidental, vai sobreviver a grande revolução tecnológica, em pleno movimento?" (Themisłocles Cavalcanti "As implicações sociais do progresso tecnológico", Carta Mensad n. ${ }^{\circ}$ 40, pág. 13)".

Não nos iludamos, pois; qualquer processo de crescimento econômico, para o caso brasileiro, deve ater-se às falhas estruturais da nossa economia e à conjuntura social altamente pressionada. A extrama desigualdade de rendas individuais, as disparidades regionais da economia, o crescente endividamente nacional, a falta de diversificação da nossa pauta de exportações com a prevalếncia de produtos primários de preços vulneráveis, o não ajustamento da estrutura jurídico-administrativa às modificações sociais e econômicas sempre mais imperativas, representam "pontos de estrangulamento" a 
serem supridos, necessàriamente, através da equação simultânea de tôdas essas questões que se inter-associam.

Tenhamos, para a equação do desenvolvimento, sempre presente esta magnífica diretiva de Myrdal: "E' ilusão acreditar que, nas condições existentes - e mais especialmente, com os poderes distribuidos por tôdas as organizações dentro da infra-estrutura e que são principalmente organizações de produtores no sentido explicado acima - o equilíbrio de uma economia nacional possa ser restaurado meramente por contrôles monetários e financeiros gerais, como em tempos ídos "(Gunnar Myrdal, ob. cit., pág. 126").

\section{8 - POUPANÇA NACIONAL}

As economias subdesenvolvidas, carentes de capital, sofrem simultâneamente a pressão do consumo. Vimos ser bastante sintomática a propensão ao consumo nas economias não desenvolvidas, por natural decorrência da aspiração que todos tem a um nível de vida mais elevado. Esta propensão ao consumo é assinalada pelo Grupo Misto BNDE-CEPAL: "Os grupos de renda menor tenderão a aplicar sua maior receita na melhoria dos respectivos padrões de vida e muito pouco realmente se pode dêles esperar no que concerne à poupança. Os grupos de renda mais elevada apresentam uma capacidade maior de poupança mas também tenderão a aumentar o consumo com a adoção de novos e luxuosos padrões de vida "(Grupo Misto BNDE-CEPAL, "Análise e Projeções do Desenvolvimento Econômico", 1957, pág. 5").

O consumo diferido ou seja a poupança, determina o lastro necessário ao investimento. O coeficiente dêste está na proporção direta do coeficiente de poupança.

Sendo muito diminuta a capacidade de poupança, esta deve ser complementada pelo capital estrangeiro. Outras vezes "êsses obstáculos que se opõem à ampliação da poupança nacional têm levado com frequência à substituição da poupança espontânea por métodos de financiamentos inflacionários, os quais resultam em uma diminuição da renda real para os setores mais pobres da população" (Grupo Misto BNDE-CEPAL, "Análise e Projeções do Desenvolvimento Econômico", 1957, pág. 5)".

Roberto Campos, com sua inconteste autoridade, afirma: "Dificilmente a inflação aumentará os recursos, a poupança real da economia" (Roberto Campos, "Programa de Estabilização Monetária, Carta Mensal, ano IV, n. ${ }^{\circ} 48$, pág. 4)".

Muitos Países não desenvolvidos, defrontando-se com tal impecilho à poupança, têm apelado a processos inflacionários, obtendo 
aumento da poupança mas a um custo social bastante alto e ensejando perigosas situações de instabilidade. O próprio Campos, no mesmo trabalho, reconhece que "em período curto a inflação pode aumentar a poupança real da economia, agindo como uma tributação privada do empresário sôbre o consumidor. Na medida em que a inflação seja uma inflação de rendimentos e que os salários não acompanhem os preços, é possível uma transferência de rendimentos da classe assalariada para a classe empresária. Isto, na coincidência das demais condições, significaria um aumento da poupança real, se não fôssem os fatôres negativos que cêdo entorpecem êsse processo" (ídem, ídem).

Deparamos, assim, no respeitante ao processo inicial para acelerar a expansão econômica, com êste dilema: forçando a inflação para acelerar o fluxo dos investimentos, estaremos anemizando a poupança real; sem suficiente taxa de poupança não obteremos, jamais, o lastro necessário para a impulsão dos investimentos. Em tais condições, estaremos na dependência sempre maior de capitais estrangeiros e jamais conseguiríamos estratificar a nossa economia em têrmos de real independência. $E^{\prime}$ verdade que tais dificuldades fazem com que a poupança deficiente seja complementada pelo capital es. trangeiro, na forma de investimentos. O essencial, porém, é ter presente que tal colaboração é sempre um expediente transitório, podendo ser gradativamente prescindido após o fortalecimento da poupança interna pelo aumento da renda, ou aceito em continuidade para maior fortalecimento de ambas.

De qualquer modo, porém, a taxa de desenvolvimento está na dependência direta da taxa de poupança.

\section{9 - POUPANÇA E INVESTIMENTO}

Pajiste em trabalho sob o título "Investimentos", lembra que "a teoria econômica atual estabelece uma diferença entre as noções de poupança e de investimento, ausente nas óbras clássicas" (Bernard Pajiste "Investimentos", Digesto Econômico, n. 102, pág. 90)". O mesmo Autor lembra que tal distinção surgiu com a economia industrial, considerada, na sociedade atual, fator básico e determinante. Tal não ocorria na economia agrícola primitiva, que precedeu a fase atual, porquanto aquela poude identificar duas noções diversas quais sejam "poupança" e "investimento", porque o desejo de fazer economias tinha como justificação a possibilidade de realizar um investimento. A relação entre poupança e investimento era direta. "A agricultura primitiva se encontrava, portanto, em uma situação na qual o consumo tendia a se identificar com a totalidade da renda real líquida. O montante destinado a ser investido determinava o 
valor da poupança e esta última diminuía o consumo total e corrente da família do agricultor, de modo a preservar os fundos neces. sários ao investimento. A poupança não representava senão a diferença entre a renda real líquida e o consumo e era igual ao investimento "(Pajiste, Dijesto Econômico n.ํ 102, pág. 90).

Também Samuelson acentúa essa correlação na fase primitiva do nosso mundo econômico "(Paul A. Samuelson "Introdução à Análise Econômica", ed. Agir, vol. II, 1952, pág. 4)".

Ficou examinado, anteriormente as dificuldades com que se defrontam os países de economias não desenvolvidas, para pbterem taxa mais elevada de expansão, uma vez que a taxa de poupança é muito reduzida e a propensão ao consumo, nessas economias, é geralmente acentuada. Dias Carneiro em notável trabalho nos alerta: "Pressupor, no Brasil de hoje, em contato pelos meios modernos de comunicação com hábitos de países industrializados, que, dada liberdade à população, poupará ela automáticamente parcela considerável da sua renda ou parte considérável do incremento dessa renda, é otimismo que os fatos não justificam. A evidência de tal propensão indica que não se deve depositar o destino do programa do desenvolvimento econômico do país na capacidade de poupança de sua população "(Dias Carneiro, "Introdução ao Desenvolvimento Econômico", Ref. de "Ciência Econômica, n. ${ }^{\circ}$ 103, pág. 74 e 75").

Não resta dúvida, assim, que sendo quase impossível diminuir - consumo para se obter um lastro necessário para inversões, necessário se torna um apêlo aos capitais estrangeiros, até que a renda cresça em índice suficiente para poder gerar inversões próprias, derivadas de poupanças já então voluntárias. Difícilmente, como vemos, as economias em desenvolvimento inicial poderão prescindir de fórmas para estabelecer uma política de pressão para a capitalização interna, sem deixar de socorrer-se, simultâneamente, de investimentos externos, em rigorosa escala de prioridades. Utilizamos a expressão "política de pressão" porquanto os fundos disponíveis nessas sociedades econômicas ainda incipientes e uma preponderância da atividade agrícola, devem ser capitalizados, por certo período, de forma compulsória.

\section{0 - tAXA DE POUPANÇA NA AMÉRICA LATINA}

A questão relacionada com a taxa de poupança necessária para imprimir às economias subdesenvolvidas um rítmo de crescimento, de modo a gradativamente poderem ir dispensando as pressões ou os empréstimos do estrangeiro, tem sido objeto de inúmeros e aprofundados estudos, entre nós, como o denota extensa bibliografia. 
A taxa de poupança influi nas taxas de investimentos e da renda nacional, propiciando o incremento na expansão econômica.

Furłado, em notas à tradução de um trabalho de Prebisch, por nós já citado ("Relações entre crescimento da população, formação de capital e as oportunidades de emprêgo nos países subdesenvolvidos ${ }^{\prime \prime}$ ), oferece-nos preciosos subsídios a respeito da taxa ou coeficiente médio de inversões brutas, necessária para propiciar o crescimento regular e gradativo da renda nacional, até ser atingido um nível tal de expansão, de modo a permitir a diminuição no apêlo aos capitais externos.

Primeiramente é necessário estabelecer o coeficiente da renda bruta, por habitante. A renda per capiła, na América Latina, entre 1940 e 1953, aumentou à taxa anual de 2,6 por cento, o que, combinado com um crescimento de 2,2 por cento anual na população, dá-nos uma taxa global de 4,9 por cento ao ano na renda bruto do conjunto latino-americano. Eliminando-se a influência decorrente da melhoria nos preços do intercâmbio ocorrida após a crise de 1930, responsável pela quinta parte do crescimento da renda global, podemos estabelecer que essa taxa global de crescimento da renda bruta latino-americana, por ano, tem sido da ordem de 4,1\%.

Se tal crescimento da renda bruta se mantivesse nessa mesma proporção de 4,1\%, a América Latina poderia, dentro de 25 anos, atingir a têrça parte da renda bruta "per capita" atual dos Estados Unidos. "Para conseguí-la seria necessária um coeficiente de inversões brutas de 20 por cento que equivale a uma taxa líquida de 13,3 por cento. Se se quizer perceber o que isto significa, deve-se recordar que nos anos mais favoráveis da relação de preços a inversão chegou a um coeficiente bruto máximo de 18 por cento no conjunto da América Latina. Desta taxa bruta de 20 por cento, cêrca de 11,1 por cento seriam necessários para absorver nas distintas atividades a incremento da população e repor o capital existente compensando sua depreciação; e os 8,2 por cento restantes, para acrescentar à produtividade e a renda por habitante na forma referida "(Raul Prebisch, "Relações entre crescimento da população, formação de capital e as oportunidades de émprêgos nos países subdesenvolvidos", in- Economia Brasileira, n. ${ }^{\circ} 3$, pág. 138)“.

\section{1 - TAXA DE POUPANÇA NO BRASIL}

Podemos estabelecer, para a economia brasileira, os mesmos índices acima, encarados globalmente, para a economia da América Latina. "Para se obter um crescimento anual da renda bruta "per capita" de 4,1 por cento é necessário aumentar em 6,2 por cento a renda total, levando-se em conta o aumento da população. Isto exige 
por sua vez uma taxa de inversão líquida de 13,3 por cento $(6,2$ dividido por 0,46 que é a relação produto capital). A inversão líquida deve-se somar a depreciação do capital existente, estimada em 3,1 por cento dêste último e, por conseguinte, em 6,7 por cento da renda $(3,1$ dividido por 0,46$)$. A inversão bruta anual necessária será, portanto, de 20 por cento da renda bruta $(6,7$ mais 13,3$)$ "(Celso Furtado, notas à tradução do trabalho anterior de Prebisch, "Relações entre crescimento da população, formação de capital e as oportunidades de emprêgo nos países subdesenvolvidos", in- Economia Brasileira, n. ${ }^{\circ} 3$, pág. $\left.138^{\prime \prime}\right)$.

Qual o teôr da poupança própria no Brasil? Os técnicos não julgam prudente, nas condições atuais da nossa economia, calculá-la em nível superior ao índice de 14 por cento da renda bruta. Portanto, para atingir o coeficiente anual de inversão bruta, necessário se torna o apêlo ao capital estrangeiro para completar os restantes 6 por cento, ou mais se a poupança própria não atingir $o$ índice de 14 por cento.

Roberto Campos, com sua habitual agudeza de espírito, considera como os problemas mais delicados do desenvolvimento econômico latino-americano, a desafiarem a imaginação dos estadistas e economistas, os relacionados com a poupança, a educação e a técnologia. A respeito da poupança assinala: "O primeiro é o incremento da taxa de poupança doméstica; donde a necessidade de formulação imaginativa de técnicas para incrementá-las, sem prejuizo dos esforços ingentes que devem ser feitos para estimular o influxo de capitais estrangeiros" (Roberto Campos" Temas da Economia Latino-Americana", conferência, in- Rev. do Conselho Nacional de Economia, ano $\mathrm{VI}, \mathrm{n}^{\circ} 45$, pág. $\left.15^{\prime \prime}\right)$.

Os métodos de captação das poupanças, entre nós, conforme apreciação do mesmo Autor, têm sido tímidamente experimentados. $\mathrm{Na}$ verdade o nosso sistema fiscal evoluiu, nos últimos meses, no sentido de transformar-se em imprescindível instrumento de captação da poupança pública, introduzindo a opção fiscal, pela qual os acréscimos de tributos sôbre a renda, sôbre lucros não distribuidos ou sôbre outras áreas de incidência fiscal, poderão ser reduzidos ou eliminados, se o contribuinte se utilizar da opção de aplicar tais recursos em setores definidos como prioritários para o desenvolvimento econômico. O "milagre" da SUDENE, a revitalizar o Nordeste e a pavimentação das estradas através do impôsto único sôbre combustíveis e pelo retôrno de quotas-combustíveis e pelo retôrno de quotas aos Municípios, representam exemplos flagrantes da formulação imaginativa (que está longe de estar esgotada) para propiciar técnicas de fomento à poupança pública com objetivos desenvolvi- 
mentistas. Esta, também, a opinião de Pajiste: "O Estado social, com as funções múltiplas que a democracia amplia sem cessar, e sobretudo a atividade econômica provocada por um processo de fiscalização redistributiva, determinaram uma outra mudança no campo destas duas ações econômicas. A poupança e o investimento foram influenciados pela ação estatal, que teve como consequência os submeter também aos efeitos da política geral dos govêrnos. A economia pública reparte hoje, com a privada, as razões e os motivos que estão na base das decisões que determinam a criação e o volume da poupança e de investimentos" (Bernard Pajiste, obr. cit., pág. 91“).

Longe de nós pretender que o desenvolvimento econômico seja realizado por compulsão, negando o espírito de empreendimento do setor privado. A economia nacional, apesar das extremas dificuldades com que se defronta, não está sofrendo um processo de estagnação. A sua expansão industrial e a soma dos investimentos privados, em equipamentos e instalações, demonstram o espírito de progresso a dominar nas classes produtoras brasileiras. O desenvolvimento econômico brasileiro não pode fundamentar-se apenas em causas exógenas; não pode ser exclusivamente induzido, aguardando os produtores a fixação, pelo Estado, da soma e distribuição dos investimentos necessários à obtenção de determinado rítmo de crescimento da renda nacional. O Brasil possui suficientes possibilidades endógenas de progresso. Daí as naturais cautelas ao adotar-se uma teoria do desenvolvimento econômico derivado ou planejado, conforme a oportuna sugestão de Bailão:

"Essas e outras reformas poderão, e deverão, ser levadas a efeito dentro das regras do jôgo da livre iniciativa e da liberdade. Sua finalidade é apressar o rítmo do nosso desenvolvimento. E, como acentuou, recentemente, o professor Galbraith, assessor do ilustre Presidente Kennedy, "o objetivo de um país em desenvolvimento pode ser resumido ràpidamente: colocar-se o mais depressa possível no século $\mathrm{XX}$ e dispor dos elementos de bem-estar individual e coletivo - alimentos, roupas, instrução, serviços sanitários, domicílio, diversão e automóvel - que representam, para todos os espíritos, do campo e da cidade, burgueses ou bolchevistas, a existência do século XX. Aqui e alí, há os que não se importam com isso. Mas, segundo minhas observações, o mais monástico cristão, o mais contemplativo budista e o mais devotado gandista, não se podem considerar completamente seguros contra os encantos da bicicleta, da motoneta ou do rádio transistor "(Jamil Munhoz Bailão "Conjuntura Econômica-Financeira do Brasil", rev. Conselho Nacional de Economia, ano XII, n. 2, pág. 281“). 
Embora não sendo o principal, o problema da poupança e do seu estímulo, para a formação do capital, é dos mais característicos no processo do desenvolvimento econômico.

\section{2 - RELAÇÃo CAPITAL - PROdUtO}

Roquete Reis, procedendo lúcida análise crítica do "Plano de Ação Econômica do Govêrno Revolucionário" (PAEG), acentúa a importância de que se reveste a questão relacionada com o tema "capital - produto" para o desenvolvimento econômico. "Ora, o Desenvolvimento é, entre outras variáveis, função da taxa de inversão (quer dizer, da percentagem da Renda que é transformada em investimentos) e da Relação Produto-Capital (que nos diz quantas unidades adicionais de Renda são geradas pelo acréscimo de uma unidade de capital). Isto leva a que pode haver crescimento (traduzido em aumento da renda real, por habitante) mesmo quando seja declinante a Taxa de Inversão; tal se daria se ocorresse um apreciável aumento de relação Produto - Capital, o que traduz uma nova orientação dos investimentos para setores menos exigentes em Capital, como sóem ser as indústrias leves e a agricultura. Da mesma forma, pode haver estagnação e até retrocesso apesar da elevação da Taxa de Inversão, quando diminuisse significativamente a relação Produto - Capital em decorrência de uma nova alocação de recursos em setores de uso intensivo de Capital (como as indústrias pesadas, a educação e a saúde)" (Fernando Roquette Reis "Desinflação e Desenvolvimento", rev. "Mensagem Econômica", ano XIV, n. ${ }^{\circ} 156$, pág. $4)^{\prime \prime}$.

Sabemos que vários fatôres influem no crescimento da renda e do produto. Os fundamentais para êsse processo de expansão da renda e do produto, são a formação de capital (ou taxa de investimento) e a produtividade média do capital, ou seja a razão produtocapiral. Atualmente também é usual a recíproca dessa razão, utilizando-se a razão capital - produto, também designada "coeficiente de capital".

No Relatório do Grupo Misto BNDE-CEPAL, encontramos subsídios bastante claros para a compreensão e a importância dessa relação: A expressão "relação produto-capital" é relativamente nova na ciência econômica. Ela está, no entanto, intimamente ligada aos conceitos clássicos de "composição orgânica do capital", de "rotação do capital" e de "período médio de produção", que se referem à relação existente entre o volume do equipamento produtivo e os outros fatôres, ou à produção real de mercadorias e serviços, e demonstraram que, quanto mais um país aumentasse seu estóque de capital, maior seria o período de gestação ou maturação do processo pro- 
dutivo" (Análise e Projeções do Desenvolvimento Econômico", Grupo Misió BNDE-CEPAL, pág. 28)".

Temos, assim, que a razão produto-capital ou produtividade do capital é a relação existente num período dado, entre o produto nacional e o capital que participou na sua produção. Conveniente é lembrar que "ao lado da relação produto-capital global, existe também as relações produto-capital parciais para os diversos setores da economia, e mesmo para as diferentes emprêsas dentro de cada setor" (Pierre Van Der Meiren, "Técnica do Planejamento Nacional de Economia, ano $\left(\mathrm{V}, \mathrm{n} .^{\circ} 36 \text {, pág. } 15\right)^{\prime \prime}$.

\section{3 - IMPORTÂNCIA DA RELAÇÃO PRODUTO - CAPITAL NA ANÁLISE DO DESENVOLVIMENTO}

$\mathrm{Na}$ análise do processo do desenvolvimento a relação produtocapital é imprescindível, pois sôbre êle influem variados fatôres, todos de vital importância, como os estoques, o gráu de utilização de capital, a composição de capital e o período de maturação do investimento. O mesmo economista ressalta a magnitude de cada um dêsses fatôres:

"1 - Se o conceito de capital inclue os esíoques, é claro que as variações dos estoques devem ser consideradas como investimento. Um aumento nos estoques terá como consequência reduzir a razão produto - capital. 2 - O grau de utilização do capital é outro fator importante. Quando existe uma capacidade de produção inutilizada, o produto nacional pode aumentar sem os investimentos adicionais; por exemplo, no caso em que a procura interna ou as exportações aumentem. 3 - Também a composição do capital e 4 - o período de maturação dos investimentos são elementos importantes: quando o capital ou os investimentos consistem principalmente em inversões agrícolas ou edifícios, a razão produto-capital será menor do que nos casos em que os investimentos se concentrem em equipamentos industriais.

Também há uma decolagem entre o momento do investimento e o momento em que os produtos adicionais chegam ao mercado. Êste período de małuração varia segundo a natureza das inversões, mas em geral grandes inversões em usinas elétricas, meios de transporte (capital social) têm um período de gestação de vários anos "(ídem, ídem)".

Gudin, em interessante estudo, declara que o problema do nosso desenvolvimento, no respeitante à escolha dos investimentos, deve partir do princípio de que uma determinada soma de capital dê 
lugar ao maior incremento possível do Produto Nacional. Isto pelo motivo de que, em nossa economia, o capital juntamente com a capacidade técnica e administrativa (Know-how) são os fatôres mais escasos.

Reconhece, o mesmo tratadista que a famosa relação, conhecida na literatura econômica anglo-saxônica pela expressão de "Capital Output Rativ"? é um dos mais importantes temas a considerar no problema do desenvolvimento econômico.

E passa a alinhar os seguintes exemplos, bastante ilustrativos dessa importância.

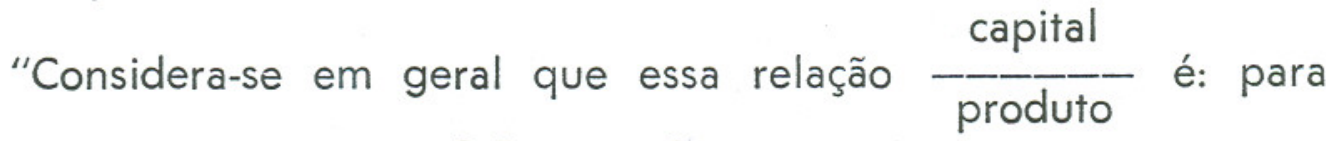
manufaturas de ordem $\frac{2,5}{1}$ e $\frac{3}{1}$; para serviços de utilidade pública $-\frac{5}{1},-\frac{6}{1}$ e $-\frac{7}{1}-$;

Na agricultura pode fàcilmente atingir $\frac{1}{1}$, se não mais;

para construções de casas cêrca de $\frac{10}{1}$.

\section{4 - ESCALA DE INVESTIMENTOS POR DECORRÊNCIA DA ANÁLISE DA RELAÇÃO CAPITAL - PRODUTO}

Vê-se, por êsses algarismos o quanto é vantajoso encaminhar os recursos de que podemos lançar mãos, de preferência para a agricultura e a indústria manufatureira. Mas de outro lado, é preciso lembrar que o desenvolvimento dêsses dois setôres também não se pode realizar sem o desenvolvimento paralelo dos serviços de utilidade pública, especialmente transportes e energia elétrica, e também das construções indispensáveis à habitação da população crescente, quando fôr o caso. Êstes algarismos mostram também que deveríamos encaminhar, de preferência, os capitais estrangeiros para os Serviços de Utilidade Pública, onde a relação capital-produto é alta e onde o volume de capital exigido é muito grande. Vê-se, de outro lado como deveríamos exercer tôda a possível parcimônia nos investimentos para construções residenciais (cuja redução capital produto se aproxima de 10). Êste último corolário contraría frontalmente a orientação dos que se deixam seduzir pelos encantos do urbanismo e dos arranha-céus, tomando a macrocefalia das cidades como índice de progresso do país "(Eugênio Gudin "Desenvolvimento e Equilíbrio" in- Carta Mensal, ano IV, n. ${ }^{\circ} 39$, pág. 43)". 
Percebemos, assim, que a economia brasileira está a exigir investimentos de vulto, para atender os setôres básicos ao seu desenvolvimento. Indústria química, usinas, telecomunicações, águas e esgôtos, são alguns dêsses setôres indispensáveis à estrutura produtiva do país, todos êles diminuindo a relação produto-capital e exigindo, como recíproca, um acréscimo mais que proporcional da Taxa de Inversão.

Inteira razão, assim, cabe a Prebisch, quando declara que o desenvolvimento econômico não é uma mera ampliação do que hoje existe. $E^{\prime}$ um processo de fortes mudanças estruturais provocadas por um fenômeno de evidente simplicidade, mas de profundas consequências.

A política econômica, para os países subdesenvolvidos como o Brasil, e tendo em vista que a nossa taxa de inversão é hoje menor do que na década de 50, deveria volver-se para os setôres menos exigentes em Capital, como as indústrias leves e a agricultura. ("Análise e Projeções do Desenvolvimento Econômico", Grupo Misło BNDE -CEPAL, pág. $25^{\prime \prime}$ ).

De suma importância, nas economias em desenvolvimento será a relação produto-capital ou seja a produtividade média do capital. Juntamente com a taxa de investimentos, como já se verificou, a relação produto-capital, representa fatôr indispensável para o crescimento da renda e do produto. Os estudos sôbre a produtividade do capital e sua evolução nos países subdesenvolvidos, estão ainda em fase inicial.

Mesmo assim podemos contar com alguns dados estatísticos a respeito, embora a exatidão das estimativas seja variável. A Secretaria Executiva da CEPAL, com base no Censo Industrial de 1940 e sôbre os investimentos líquidos ocorridos no período de 1939 1953, apresenta, para tal período, a relação média de 0,52, tendo subido de 0,49 em 1939 para 0,57 em 1947-1948 e atingindo 0,53 em 1953.

Essa relação é bastante elevada, comparativamente a de períodos anteriores, indicando melhor aproveitamento dos recursos naturais e melhor utilização do capital e da mão-de-obra.

\section{5 - PROPENSÃO AO CONSUMO}

Ao tratar da Poupança Nacional dissémos ser bastante sintomáticas, nas economias subdesenvolvidas, a propensão ao consumo.

Tal fator assume primordial importância, pois vai afetar, diretamente, o potencial do capital a ser formado. 
A economia dos países subdesenvolvidos, como é óbvio, é carente de capital; paralelamente a tal escassez, a sua tendência é a do consumo absorver ponderável parte em bens de consumo, diminuindo a possibilidade de formação de investimentos suficientes para a sua aceleração.

Observa-se, entre nós - como em tôdos os países ainda em desenvolvimento - uma generalizada aspiração por um estilo moderno de vida, conforme observa Gudin. Todos aspiram confôrto idêntico ao propiciado pelas economias altamente desenvolvidas; e em. bora a renda per-capita do brasileiro seja ínfima, cresce a parcela dos seus gastos, em bens de consumo duráveis.

Essa pressão do consumo, conforme leis econômicas bastante conhecidas, independe muitas vêzes do próprio teôr do rendimento individual. Nem o baixo índice da renda per-capita, entre nós, é de molde a diminuir o consumo, quer dos bens de baixa elasticidade ou daquêles de procura inelástica.

Os orçamentos familiares da massa trabalhadora e de parte bastante ponderável da classe média, no Brasil, se mostram geralmente deficitários. Vivem, essas famílias, em quase permanente estado de iliquidez, sendo/cada vez mais acentuado o volume dos pagamentos diferidos.

Tal situação determina consequências imprevisíveis em economias de baixas rendas individuais, porquanto a acumulação de capitais implica, consoante é conhecido, em a coletividade se abster de consumir, num determinado espaço de tempo, tudo aquilo que fôr decorrente da sua atividade produtiva naquele mesmo espaço de tempo. Sem tal compressão do consumo nenhum país poderá acumular para a aquisição ou produção de bens de investimentos (ferramentas, máquinas, fábricas, estradas, etc).

A relação entre o que cada indivíduo gasta $\mathrm{em}$ bens comuns Assim, se chamarmos $\mathbf{C}$ as despesas com o consumo de um indivíduo e $\mathbf{R}$ a sua renda, teremos que a sua propensão para consumir e a sua renda é o que Keynes chamou a propensão para consumir. será $C / R$. Daí, na igualdade $\mathbf{P C}=\mathbf{C} / \mathbf{R}$, a propensão para consumir será tanto mais elevada quanto menor fôr o fator $\mathbf{R}$ da fração.

\section{6 - A PROPENSÃO DE CONSUMIR, NO BRASIL}

A propencão média da população brasileira, para consumir é portanto muito mais elevada do que a registrada para a população de rendas mais elevadas, como a canadense ou a norte-americana. Isso porque, na economia brasileira, sendo maior o contingente de individuos nas classes mais baixas de rendimentos auferidos, a dis- 
tribuição da renda nacional, entre nós, é muito mais irregular e um maior pêso nas classes menos favorecidas.

Para os Estados Unidos, cuja renda nacional per-capita é das mais elevadas, calcula-se que seja da ordem de $20 \%$ a parte da produção corrente que não é gasta em bens de consumo. O valor absoluto da renda total norte-americana supera a cifra de 500 biIhões de dólares, o que faz crer existir, nêsse país, um mínimo de 100 bilhões de dólares em disponibilidade que são poupadas anualmente, para serem invertidas em bens de produção. Para o Brasil, conforme estimativa de 1947, pela Missão Abbink, não ultrapassa de $10 \%$ da nossa renda o que poupamos ao consumo.

Verifica-se, pelo exposto, a magnitude do fator propensão para consumir, a anemizar, nos países subdesenvolvidos, a sua já incipiente capacidade de poupança. Consequentemente, o analista deverá cogitar, também, da poupança forçada, embora seus inevitáveis malefícios em economias como a nossa, onde se observa a ocupação plena dos fatôres da produção. Para economias nestas condições, a poupança forçada determinará, inevitàvelmente, o crescimento da índice de preços; para as economias desenvolvidas, onde se observa a existência de fatôres de produção em estado ocioso, em períodos normais, a expansão monetária decorrente da poupança forçada permite a utilização de tais fatôres e o aumento da renda nacional, sendo bem mais reduzida a elevação dos preços.

\section{7 - FATÔRES DE DESENVOLVIMENTO ECONÔMICO}

Dias Carneiro nos fornece precisa definição de desenvolvimento, a qual encerra alguns dos seus fatôres fundamentais:

"O conceito de desenvolvimento econômico se define, entre outros modos, como a elevação ao máximo compatível com as condições de equilíbrio social e econômico interno e externo, da taxa de crescimento do produto nacional líquido e real per-capita. Desenvolvimento econômico, assim entendido, é um ato da vontade política e social que objetiva o aumento do padrão de vida do povo, noção esta conceituada como significando a medida da relação entre certo conjunto de necessidade e certo sistema de produção que, compensada a participação dos fatôres no circuito da riqueza nacional, transforme o desejo de satisfação dessas necessidades em procura efetiva no mercado "(O . A. Dias Carneiro, "Três obstáculos ao Desenvolvimento Econômico do Brasil", Rev. Cons. Nac. de Economia, ano VII, n. 2 , pág. 115)".

Deparamos, assim, com a multiplicidade dos fatôres a influen- 
ciarem no processo do desenvolvimento: o padrão de vida, como o afirma o mesmo economista, abrange quer a produção de bens de consumo, quer a produção de bens de capital fixo e circulante; pressupõe a existência, no mercado, de procura efetiva dêsses bens por parte dos indivíduos e das emprêsas integrantes da economia. Evidenciam-se, assim, prossegue Carneiro, as relações de equilíbrio que necessáriamente existem entre o "ótimo" de mão de obra e capital nas zonas rural e urbana; o progresso técnico e o gráu de produtividade do capital e do trabalho nessas duas regiões; o índice de riqueza nacional; e o volume, rítmo, orientação e distribuição qualitativa do investimento disponível para se manter a taxa de crescimento do produto nacional líquido e real acima da taxa de reprodução demográfica (ídem, ídem, pág. 115).

Percebe-se, assim, a multiplicidade dos fatôres no processo desenvolvimentista. Os fatôres básicos são os mesmos do processo produtivo: natureza, trabalho e capital. Além dêsses componentes do desenvolvimento, deparamos com os elementos do processo em sí do mesmo fenômeno de expansão, que compreende as modificações na tecnologia, na escala de produção e na obtenção de recursos. "Desde logo, a distinção entre os componentes e o processo é arbitrária, porquanto os componentes sofrem modificações no transcurso do crescimento e o processo pode ser descrito, também, como as modificações no desenvolvimento dos recursos do capital e das pessoas" (Kindleberger, ob. cit. pág. 10)".

\section{8 - ASPECTOS SOCIOLÓGICOS DO DESENVOLVIMENTO ECONÔMICO}

Costa Pinto afirma, com segurança e propriedade, que o desenvolvimento econômico é um problema muito mais sociológico do que estrítamente econômico. "Em boa parte, o que hoje os economistas, estadistas e administradores estudam, planejam e executam como "desenvolvimento econômico" - é em certo sentido, uma configuração específica, históricamente definida, do processo geral da mudança social "(luiz Aguiar Cosła Pinto "O Desenvolvimento: Seus processos e seus obstáculos", Rev. do Cons. Nac. de Economia, ano XII, n. ${ }^{\circ}$, pág. 521)". O importante, nas mudanças de estrutura social, é que as transformações não se operam simultâneamente em tôdas as suas partes; umas se transformam em rítmo mais acelerado, outras mais vagarosamente. A transformação das primeiras recebe a denominação de impulsão e a das segundas opera como fator de contenção. Tais fenômenos, a se operarem na estrutura social, influem na econômica, daí a importância moderna do estudo sociológico dos problemas de desenvolvimento econômico. 
A dinâmica econômica moderna muitas vêzes se depara com obstáculos bastante ponderáveis, frente a resistência para a transformação oferecida pela estrutura social. A Família, a Emprêsa, a Educação, a Ciência, ainda não adaptaram as suas estruturas às exigências da sociedade atual e podem representar sérios obstáculos ao desenvolvimento econômico. O "coronelismo" do interior é ainda reminescência de estrutura social e política já superada, mas ainda renitente à adaptar-se às novas condições sociais e econômicas. A emprêsa familiar ou fechada, é outro tremendo óbice ao desenvolvimento e à própria paz social que os empresários tanto invocam e da qual cada vez mais se distanciam, porquanto se opõem e dificultam a implantação de novos padrões, valôres e técnicas características de um estilo racional de organização de emprêsa. "Um dos setôres em que condições novas, criadas e exigidas pelo desenvolvimento, mais nitidamente se chocam com os velhos padrões de organização empresarial - é o das relações entre empregados e empregadores, onde se assiste à liquidação de tôdas as condições em que repousava o velho patriarcalismo patriarcal, sem que se observe a formação, no mesmo rítmo, de formas intsitucionais que o substituam" (ídem, ídem).

A educação e o preparo técnico do empresário é tão ou mais importante do que o do empregado. Observadores estrangeiros já manifestaram sua admiração pelo índice de produtividade da emprêsa brasileira, tendo em vista o despreparo técnico e o empirismo da maioria absoluta da classe patronal do nosso país. Isto em parte se explica pela disponibilidade dos recursos naturais em nossa economia; mas de todo o modo se trata de desperdício, a se refletir nos custos e nos preços.

\section{9 - O FATOR HUMANO NO PROCESSO DESENVOLVIMENTISTA}

Outro fator de fundamental importância na análise do desenvolvimento é o crescimento demográfico. Entre nós, atingindo o índice de $3,2 \%$ ao ano, determina a multiplicação da nossa população cada 22 anos. O rítmo do crescimento populacional brasileiro se pro cessa muito mais aceleradamente do que o do desenvolvimento, a acusar o índice de $2,2 \%$ da renda anual. Devemos, portanto, estabelecer processos de produtividade agrícola, não apenas para prover os meios de subsistência, como para economizar divisas na aquisição de gêneros alimentícios.

De Vincenzi é bastante elucidativo quando lembra que "na ver: dade, o desenvolvimento econômico é determinado pelas condições oferecidas pela ambiência física, pelas aptidões corporais e mentais 
do grupo humano (†ão importantes na recente expansão alemã), pela sua herança biológica e institucional, pelo instrumental e as técnicas de trabalho, pela estratificação social e organização política e, finalmente, pela cultura prevalecente. A variedade e a complexidade dessas determinantes dizem da dificuldade de configurar o problema do desenvolvimento e, consequentemente, de provê-lo de modo adequado "(Nelson de Vincenzi "A India planifica o seu desenvolvimento", Rev. do Conselho Nac. de Economia, ano VI, n. 47( pág. $17)^{\prime \prime}$.

Mais recentemente, diz Gudin "vários economistas, Aukrust, na Noruega, Robert Selow, na América, Niitamo na Finlândia, observaram que o incremento do capital só por si não supre uma ampliação satisfatória do aumento do Produto e que o desenvolvimento não depende sòmente das duas variáveis, capital e trabalho, sendo necessário introduzir um terceiro fator, - o "fator humano", correspondente à organização e à capacidade profissional e técnica, fator êsse cuja importância é não raro igual ou maior do que a do capital. Para estabelecer a função da produção das três variáveis, capital, trabalho e organização (chamemos assim o terceiro fator) surgem algumas dificuldades. Uma é que o fator "organização", que abrange a competência técnica e comercial de engenheiros, gerentes e operários, não é mensurável. Outra dificuldade está no desconhecimento de como uma alteração na combinação dos três fatôres influe sôbre o produto".

A estrutura produtiva, pois, é bastante complexa, sendo múltiplos os fatôres desenvolvimentistas. Tôdas influem na formação do produto interno bruto, o qual, em última análise, representa a resultante de uma ponderação de recursos por técnica a uma certa relação produto-capital, a ser afetada, necessàriamente, pela tecnologia a ser empregada na economia. Daí a procedência de Myrdal ao acentuar que "êste complexo de problemas pode, contudo, ser apreciado de vários ângulos: diferentes questões podem ser suscitadas e diferentes métodos de contato podem ser escolhidos. Na verdade, para se obter um crescimento científico equilibrado é necessário que, simultâneamente, vários estudiosos, de maneiras várias, ataquem os problemas emergentes. Consoante a grande tradição ociden. tal do humanismo liberal, o progresso, no devido tempo, assim o esperamos, se materializará como resultado de discussão e mesmo de controvérsia. "Gunnar Myrdal, "Desenvolvimento e Sub-Desenvolvimento", Rev. do Cons. Nac. de Economia, ano VI, n. 47, pág. $\left.22^{\prime \prime}\right)$. 